Article

\title{
Seismic Response Analysis of Multi-Story Steel Frames Using BRB and SCB Hybrid Bracing System
}

\author{
Rong Chen ${ }^{1, *}$, Canxing Qiu ${ }^{2, *}$ and Dongxue Hao ${ }^{1}$ \\ 1 School of Civil Engineering and Architecture, Northeast Electric Power University, Jilin 132012, China; \\ 20102291@neepu.edu.cn \\ 2 Key Laboratory of Urban Security and Disaster Engineering of Ministry of Education, Beijing University of \\ Technology, Beijing 100124, China \\ * Correspondence: 20112384@neepu.edu (R.C.); qiucanxing@bjut.edu.cn (C.Q.)
}

Received: 8 November 2019; Accepted: 23 December 2019; Published: 30 December 2019

Featured Application: The proposed bracing system provides a novel solution for controlling peak seismic responses and for eliminating residual deformation for conventional concentrically braced frames.

\begin{abstract}
Multi-story steel frames are popular building structures. For those with insufficient seismic resistance, their seismic capacity can be improved by installing buckling-restrained braces (BRBs), which is known for high energy dissipation capacity, and the corresponding frame is denoted as BRB frame (BRBF). However, BRBFs are frequently criticized because of excessive residual deformations after earthquakes, which impede the post-event repairing work and immediate occupancy. Meanwhile, self-centering braces (SCBs), which were invented with a particular purpose of eliminating residual deformation for the protected structures, underwent fast development in recent years. However, the damping capability of SCBs is relatively small because their hysteresis is characterized by a flag shape. Therefore, this paper aims to combine these two different braces to form a hybrid bracing system. A total of four combinations are proposed to seek an optimal solution. The multi-story steel frames installed with BRBs, SCBs, and combined braces are numerically investigated through nonlinear static and dynamic analyses. Interested seismic response parameters refer to the maximum story drift ratios, maximum floor accelerations, and residual story drift ratios. The seismic analysis results indicate that the frames using the combined bracing system are able to take the advantages of BRBs and SCBs.
\end{abstract}

Keywords: multi-story steel frames; self-centering bracing elements; buckling-restrained brace (BRB); seismic analysis

\section{Introduction}

Conventional multi-story steel frames were found susceptible to earthquake attacks, and the huge social and economic loss caused by catastrophic earthquakes inspired the community to explore advanced technologies to upgrade the seismic resistance of structures. Many seismic damping devices, such as those based on friction mechanism [1-3], metallic yielding behavior [4,5], and buckling-restrained braces (BRBs) [6], are representatives among many research efforts and have been applied in practice to protect the structures.

Initially, normal steel braces were installed in steel frames to enhance seismic capacity. For example, Shen et al. [7] compared normal brace and BRBs and indicated that BRB is more efficient than normal braces in earthquake resistance. Hsiao et al. [8] proposed a sophisticated model to capture the buckling behavior of normal steel braces. Simpson and Mahin [9] suggested using a strongback braced frame to 
mitigate buckling-induced weak story behavior. Being different from normal steel braces, BRBs avoid buckling-induced instability and thus show stable cyclic behavior under both tension and compression loads. Owing to their outstanding damping capacity and economical production, BRB frames (BRBFs) have become popular seismic resistant structural systems and are being widely used over many countries [10]. According to prior work [6,10], BRBs exhibited plumb hysteresis, which enables BRBFs to successfully absorb seismic energy. Sabelli et al. [6] numerically quantified the seismic demands of BRBFs. Ariyaratana and Fahnestock [11] evaluated the effect of reserve strength on the seismic performance of BRBFs. Many numerical studies can be found elsewhere [12]. However, it is noted that the plumb cyclic behavior of BRBs leads to excessive residual deformation in the global system. As reported, under earthquakes, BRBFs usually exhibited satisfactory seismic performance but were prone to producing noticeable residual deformation, even after moderate earthquakes $[6,13]$. Through the numerical analysis reported by Sabelli et al. [6], the average residual story drift ratio of multi-story BRBFs was over $0.5 \%$ when subjected to design basis earthquake (DBE) ground motion records.

Excessive residual deformations may hinder the post-event recovery of building function and repairing work and, thus, have gained increasing attention among the community of earthquake engineering [14-16]. Post-event investigations found that a lot of building structures were finally demolished and rebuilt due to unrecoverable deformation, although they performed satisfactorily during earthquakes. Recognizing the problems associated with excessive residual deformations, the community quantitatively defined several thresholds of residual deformation that correspond to several damage levels. When the residual story drift ratio was over $0.5 \%$, it would be more suggestible to rebuild a new structure rather than repairing the damaged one [17]. Besides, with the reparability, the out-of-plumb limits were also determined by the magnitudes of residual story drift ratios, which were determined to be $0.2 \%$ and $0.1 \%$ for the 3 - and 6-story frames, respectively, based on relevant analytical results [18].

Many strategies were recently proposed and found effective in reducing the residual deformation demands of BRBFs [19-26]. For example, adopting moment-resisting frame (MRF) as the backup system for BRBFs was a methodology recommended by Reference [27] from the aspect of system level. By paralleling MRF to share $25 \%$ of the total design base shear, the residual story drift ratios of BRBF was reduced remarkably although not completely eliminated [27]. Ariyaratana and Fahnestock [11] also found that the participation of MRF reduced the residual story drift ratios. In their work, the residual deformations were decreased by approximately 50\%. Combining MRF brings noticeable efficacy on reducing residual story drifts; however, it deserves further improvement because the residual story drifts were still over $0.5 \%$ upon a few earthquake records that correspond to the DBE level. As a consequence, the BRBF-MRF system still violated the reparability limit defined by a post-earthquake renaissance report [17].

As have been pointed out by prior studies [22,26,28-38], self-centering braces (SCBs) are an alternative to conventional braces because they can recover large deformation and can absorb input seismic energy. SCBs can be based on shape memory alloys (SMAs) or post-tension technology supplemented by damping sources, exhibiting a flag-shape (FS) hysteresis. The first SMA-based SCB can be traced back to the work by Dolce et al. [29]. In their study, the SMA-based SCBs consisted of a pair of superelastic SMA cables which were prestressed to a desirable extent to provide recentering capacity and energy dissipation ability, respectively, and then they were tested within a scaled reinforce concrete frame. Christopoulos et al. [30] invented an innovative SCB which explored the large elastic behavior of aramid tendons and friction damper. According to the test, the SCB exhibited full FS behavior and suffered from high axial strain level while resulting in zero structural damage. Through extensive analyses on FS single-degree-of-freedom (SDOF) systems, Christopoulos et al. [39] pointed out the benefits of increasing energy dissipation and post-yield stiffness in improving the seismic performance of self-centering structures. Researchers have proposed various improvement schemes for systems using SCBs. Such as Zhu and Zhang [22] tuned the relative amount of the prestressed and un-prestressed SMA cables to meet the energy dissipation and post-yield stiffness of SCB at a 
desirable level. In another work, the authors [40] introduced friction mechanism in SMA-based SCBs to increase the damping behavior of self-centering hysteresis. The testing results of the reduced-scale brace specimen detected that the FS cyclic behaviors were repeatable for many loading cycles without any property degradation. Erochko et al. [41] explored the friction damper, in which the friction surfaces were created inside in the SCBs to generate a plump hysteresis. Further, the SCBs were tested within a reduce-scale frame on shaking table and they performed as expected in a series of strong earthquakes and maintained a stable FS hysteresis with high damping capacity.

As have been revealed by prior studies, BRBFs have the problem of generating excessive residual deformations after earthquakes, while the self-centering concentrically braced frames (SCCBFs) have relatively low energy dissipation capability. This work comprehensively compares the seismic behavior of BRBFs, SCCBFs, and concentrically braced frames (CBFs) using hybrid bracing systems. The idea of combing BRBs and SCBs in a braced frame has never been proposed by earlier studies. To validate the proposed idea, nonlinear static and time-history analyses were carried out on the bracing system using BRBs, SCBs, and a combination of them. In the comparative analysis, interested seismic response parameters include maximum story drift ratio, maximum floor acceleration, and residual story drift ratio. Through the comparative study, it indicates that the BRBFs are featured with excessive residual deformation and that the SCCBFs are characterized by larger deformation demand. However, when the BRBs and SCBs are utilized together as the hybrid bracing system, the protected frame structures respond with improved performance, including reduced maximum deformation, controlled maximum floor acceleration, and minimized residual deformation. As well as should be noted is that, although this paper primarily analyzed the seismic performance of multi-story CBFs, the associated observations and conclusions might also provide some insights into the similar self-centering structures and systems.

\section{Cyclic Behaviors of BRB and SCB}

Figure 1 shows that the cyclic behaviors of BRB and SCB are usually simplified as a bilinear elasto-plastic and FS constitute model, respectively. The simplified models have been either experimentally or numerically validated by many prior studies $[6,13,15,20]$. As suggested in prior studies $[6,11,15]$, the post-yield stiffness ratio of BRBs is within the range of $1 \%$ to $5 \%$. In this analysis, this value for BRB is defined to 1\%. An idealized FS model is used to describe the cyclic behavior of SCB in this study. Besides with the "yielding" strength and elastic stiffness, the cyclic behavior of the FS model is determined by introducing another two critical parameters, e.g., the post-yield stiffness ratio $\alpha$ and hysteresis width $\beta$. In fact, the values of these two parameters may vary with the practical configuration of the bracing components and configurations. Through properly tuning the contribution of each individual subassembly member, the SCBs can achieve a number of combinations of $\alpha$ and $\beta$. To be consistent with the post-yield strength of BRB and to maximize the energy dissipation capacity, the values of $\alpha$ and $\beta$ currently considered for SCBs are set to be $1 \%$ and 1.0, respectively. It is noted as well, to simplify the problem, the degradation mechanism associated with stiffness and strength is excluded.

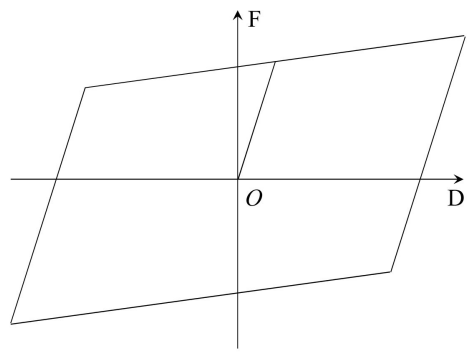

(a)

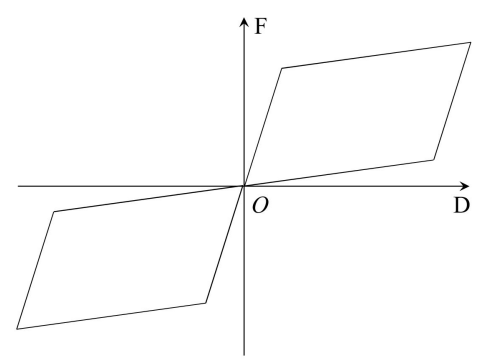

(b)

Figure 1. Cyclic behaviors of the considered braces: (a) buckling-restrained brace (BRB); (b) self-centering brace (SCB). 
As aforementioned, SCBs are assumed to perform identically as BRBs in the initial elastic stage, which is the primary premise made in the comparative analysis. In such a way, the comparison is focused on highlighting the seismic response characteristics of CBFs when different types of braces are installed. It should be noted that the "yield" behavior of SCB is analogous to that of a normal steel brace but that the structural member does not really yield. The "yield" strength of a SCB actually refers to the stiffness degradation behavior of the component. In detail, for SCBs using post-tension technique, the "yield" behavior is caused by the decompression or activation force [30] while for those based on SMAs, it stands for the strength triggering the austenite to martensite phase transformation upon loadings [29]. In this analysis, the fracture problem of braces is not considered, which follows the assumption made by a variety of earlier studies [6,13-15].

\section{Multi-Story CBF}

Sabelli et al. [6] designed a six-story BRBF that complies with the requirement of National Earthquake Hazards Reduction Program (NEHRP) [42], assuming the location is Los Angeles downtown. This frame is used in the following analysis. The same parameters of BRBs and frame members are used to be consistent with the original design. Figure 2 shows that the CBF, which was noted as 6vb2 in original study, has a chevron-bracing placement. In this study, it is renamed as S1. It has a bay width of $9.0 \mathrm{~m}$ for each single bay, and its 1st-story height is $5.5 \mathrm{~m}$, and the upper stories are $4 \mathrm{~m}$. More building information and design procedure can be found in a related work by Sabelli et al. [6]. With the aim to isolate the influence of framing mechanism, the beam-to-column rigid connections are amended to hinge type. Such a treatment also helps to release bending moment suffered by the connection area and to adapt to large rotations while maintaining the connections damage free [43]. The connection amendment weakens the lateral stiffness of the system and thus leads to a longer structural vibration period to a certain degree. Incidentally, the story number is one parameter that needs in-depth investigations in the future. The corresponding effect can be quantified by increasing and decreasing the number of stories. However, the parametric analysis on story number is not included in this work due to space limitation and current research focus.

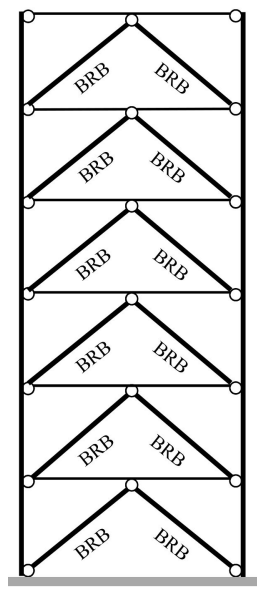

S1

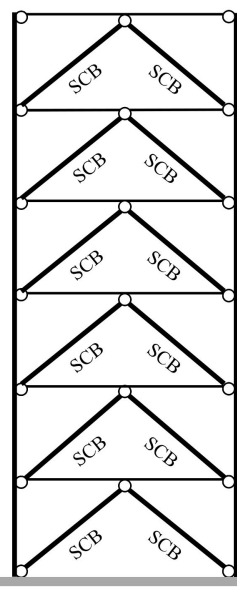

S2

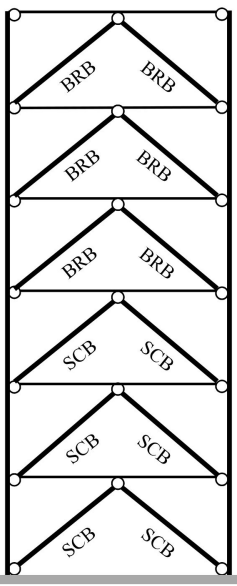

S3

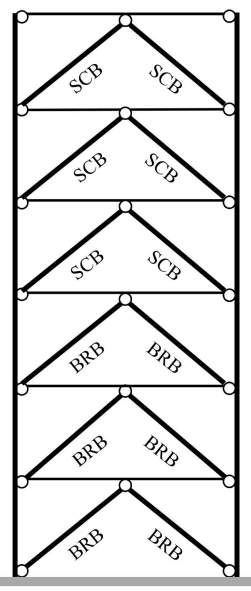

S4

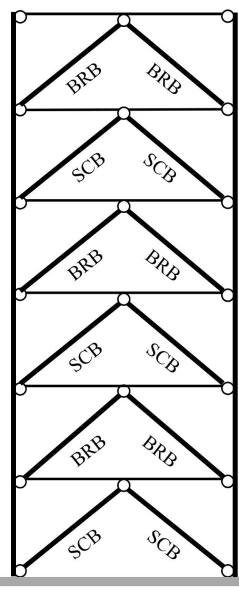

S5

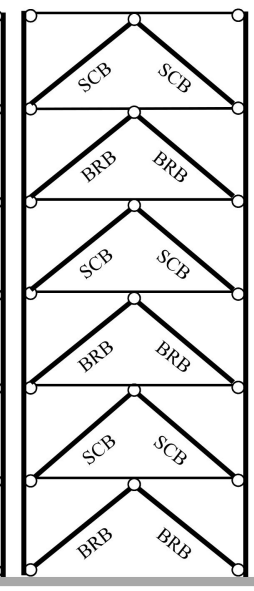

S6

Figure 2. Concentrically braced frames (CBFs) using various bracing systems.

In terms of the other frames under consideration, they are produced by substituting the BRBs in frame $\mathrm{S} 1$ with SCBs at different locations. Figure 2 shows the notation of the frames. The BRBF is denoted as $\mathrm{S1}$, and the identical SCCBF which uses SCBs throughout building height is named as S2. The effect of varying the combinations of BRBs and SCBs is intensively examined. The structures of S3 and S4 are achieved by replacing the BRBs with SCBs at the lower and upper three stories, respectively. For the structures of S5 and S6, the BRBs are replaced alternately throughout building height. Specifically, the BRBs are replaced with SCBs at the odd and even stories in S5 and S6, 
respectively. The yield strength $F_{y}$ and the elastic stiffness $k$ are defined identical for the BRBs and SCBs in every single story. Consequently, the framing structures, although they are installed with various bracing system, have exactly the same dynamic properties in the initial elastic state. According to the eigen value computation, these CBFs have a fundamental period of approximately $0.82 \mathrm{~s}$. It is also worth noting that the performance objectives under earthquakes are not explicitly specified, since the current focus is paid on seeking a solution to reduce the residual deformation of BRBFs through comparing the frames installed with different bracing systems.

\section{Numerical Model}

A total of six CBFs numerical models are created in the earthquake simulation platform OpenSees [44]. Figure 3 displays the numerical model. Figure 3 shows the building information of the prototype frame as well, which presents the cross-sectional shapes of the main members and the building dimension. The designations of $\mathrm{W} 14 \times 48, \mathrm{~W} 14 \times 132$ and $\mathrm{W} 14 \times 211$ are the steel beams and columns with wide-flange or I-shaped sections. Taking W14 $\times 48$ for example, it means the steel has a cross-sectional height of $14 \mathrm{in}$. with a unit weight of $48 \mathrm{lbs} / \mathrm{ft}$. For all stories, Table 1 includes the strength capacity and the initial axial stiffness of the braces. The beams, columns, and braces are modeled using the force-based beam-column elements, considering the displacement interpolation functions of displacement-based elements may deviate from the exact solution [45]. Columns have fixed bases and are continuously modeled throughout building height. The beam-to-column pinned connections are achieved by using two over lapped nodes. The beam and column elements are made of American Society of Testing Materials (ASTM) A992 steel material. The corresponding post-yield stiffness ratio is assumed to be 0.003 . The Rayleigh damping ratio of $5 \%$ is assumed for the first two modes. Similar to a prior treatment [46], the panel zone is not simulated, with the aim to keep the analysis time to a reasonable level. Further, to simplify the problem, the buckling and fatigue problems are excluded, and thus, the potential degradation of strength and stiffness of steel were not taken into account. In terms of the bracing components, each one is modeled as one single element with four integration points; the corresponding cross sections are an assembly of uniaxial fibers. Due to symmetry, only one bay is numerically modeled. Vertical gravity loads are applied gradually on the model, and then, dynamic analysis under horizontal seismic input is carried out. The structural torsion along with a vertical axis is not triggered.

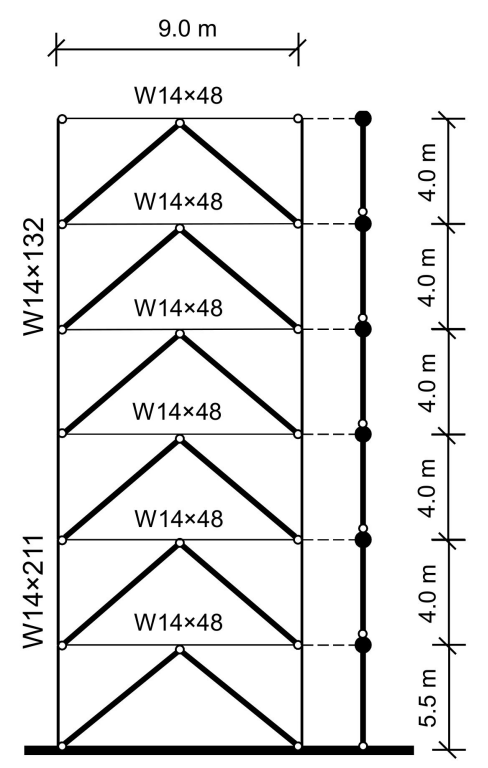

Figure 3. Modeling of the prototype frame in OpenSees. 
Table 1. Mechanical properties of the braces.

\begin{tabular}{ccc}
\hline Level & Yield Strength $\mathbf{( k N )}$ & Elastic Stiffness $\mathbf{( k N / m )}$ \\
\hline 1 & 1704 & $288 \times 10^{3}$ \\
2 & 1306 & $244 \times 10^{3}$ \\
3 & 1161 & $217 \times 10^{3}$ \\
4 & 961 & $179 \times 10^{3}$ \\
5 & 711 & $133 \times 10^{3}$ \\
6 & 394 & $73 \times 10^{3}$ \\
\hline
\end{tabular}

Figure 3 shows the tributary floor mass is idealized as concentrated mass nodes affiliated to the leaning column. The leaning column is to represent the other spans of frames that have negligible seismic resistance while carry all the building weight. The leaning column is coupled to the braced frame at each floor level in the vertical and lateral displacement directions. This column is vertically rigid and has a large cross-sectional area to carry the applied nodal mass. In the numerical model, the leaning columns are jointly connected at the adjacent levels. In such a situation, the leaning column would not provide stiffness and strength in the seismic input direction for the entire system. The total seismic mass at each floor is equally shared by the braced bays, thus each frame carries $1 / 6$ of the total floor mass. The floor and total mass of each braced frame are $1.51 \times 10^{5} \mathrm{~kg}$ and $9.06 \times 10^{5} \mathrm{~kg}$, respectively. As a result, the leaning column is able to account for the P- $\Delta$ effect while does not affect the strength or stiffness of the structure.

\section{Ground Motions}

An ensemble of earthquake ground motions containing records developed by Somerville et al. [47] is considered. There are 20 single records in this suite, which are generated for Los Angeles area having a $10 \%$ probability of exceedance over 50 years, corresponding to design-basis earthquake (DBE) hazard level. They are designated as LA01-LA20. These records cater to the soil type $S_{D}$. Figure $4 a$ plots spectral accelerations for the 5\%-damped SDOF systems under these ground motion records. Figure $4 \mathrm{~b}$ includes the earthquake records associated with the maximum considered earthquake (MCE) hazard level. It is seen that the mean spectrum over 20 records matches the design basis earthquake spectrum reasonably well. The fundamental period of the frames (i.e., $\mathrm{T}_{1}=0.82 \mathrm{~s}$ ) is of particular interest. The spectral accelerations corresponding to the fundamental period are extracted from the response spectra. The mean value of 20 individual results is $0.90 \mathrm{~g}$, which agrees very well with the result from the ground motion record LA09. Thus, the seismic performance under this single record will be examined in case study.

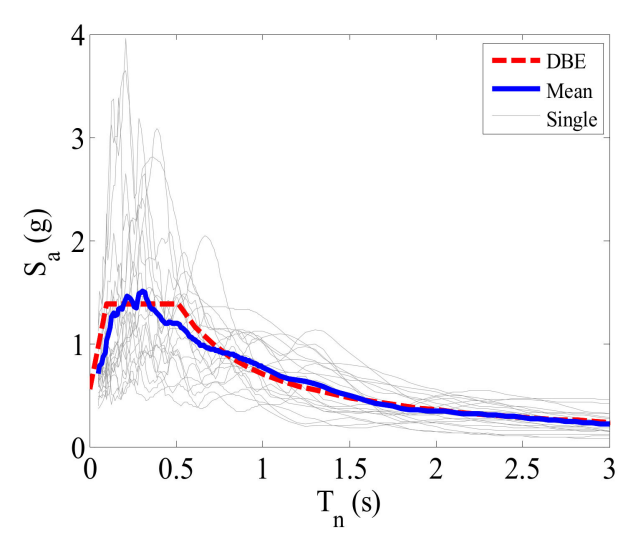

(a) Design basis earthquake (DBE)

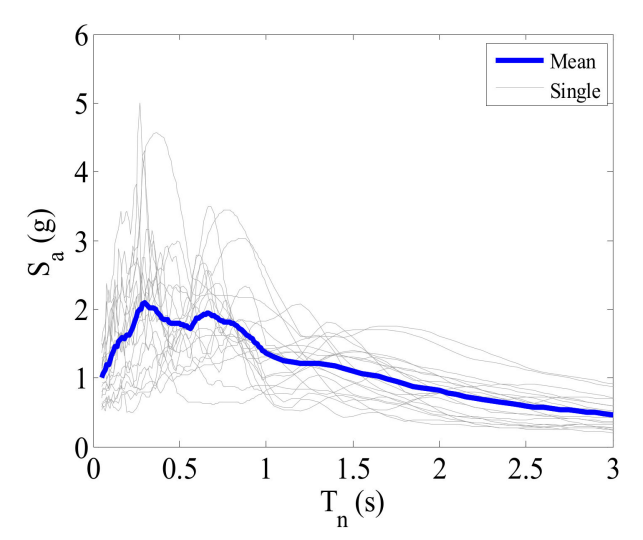

(b) Maximum considered earthquake (MCE)

Figure 4. Spectral acceleration of the 5\%-damped single-degree-of-freedom (SDOF) system of the selected ground motion records. 


\section{Pushover Analysis}

The braces are the kernel seismic resistant components of the braced frames. Figure 1 indicates that the BRB and SCB show different hysteretic behaviors upon a same cyclic loading loop. Accordingly, when installed with different braces, the $\mathrm{CBFs}$ demonstrate various nonlinear responses. Using the combined bracing system in the CBFs changes the global behavior of the framing systems, and the associated influence is firstly assessed by conducting the static pushover analysis. Gravity loads are gradually applied to the frame model prior to applying lateral forces. During the pushover procedure, the lateral force pattern compliant with the first vibration mode is applied and maintained. A control node is set at the roof level to monitor the target displacement. The roof drift ratio target is determined to $4 \%$, which is sufficiently large to deform the structure into significant inelasticity.

Figure 5 assembles the cyclic behaviors of different framing systems by building the relationship between roof drift ratio and normalized base shear. The normalized base shear refers to the entire base shear divided by total building weight. As expected, the yielding strength, initial stiffness, and post-yield stiffness ratio are exactly the same among all the considered structures, since the elastic behavior of the braces is the same. However, the unloading behaviors are noticeably different. It is seen that the BRBF exhibited full elasto-plastic hysteresis as that of BRB components, showing a post-yield stiffness ratio of approximately $1.3 \%$. In terms of the identical SCCBF, the hysteresis of the structural system is featured by purely FS behavior, which indicates the structural response is dominated by the local SCB component. Figure $5 \mathrm{c}-\mathrm{f}$ plots the hysteresis shape of the CBFs using hybrid bracing systems, indicating the resulted cyclic behavior is between the bilinear elastic-plastic hysteresis and FS hysteresis. Compared with the BRBF, S3 to S6 tend to exhibit a pinching behavior due to the recentering property offered by SCBs. Compared with the SCCBF, the hysteresis is well widened, thanks to the high energy dissipation capacity provided by the BRBs. In other words, through combining BRBs and SCBs, the original BRBF gains improved recentering capability at the cost of losing energy dissipation capacity to a certain degree.

The assessment of global cyclic properties of different framing systems indicates the energy dissipation capacity of CBFs using hybrid braces lower than the BRBF. On the other hand, compared with the SCCBF, the maximum possible residual deformation, which usually refers to the intersection point of unloading line and deformation axis [48] is increased by introducing BRBs. However, the static analytical results do not necessarily reflect the dynamic properties under earthquakes. Thus, it is crucial to evaluate the effect of using a hybrid bracing system on the seismic behavior by nonlinear time history analysis.

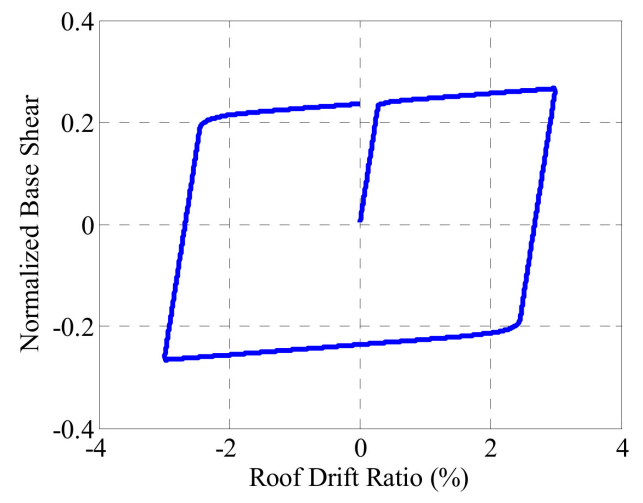

(a)

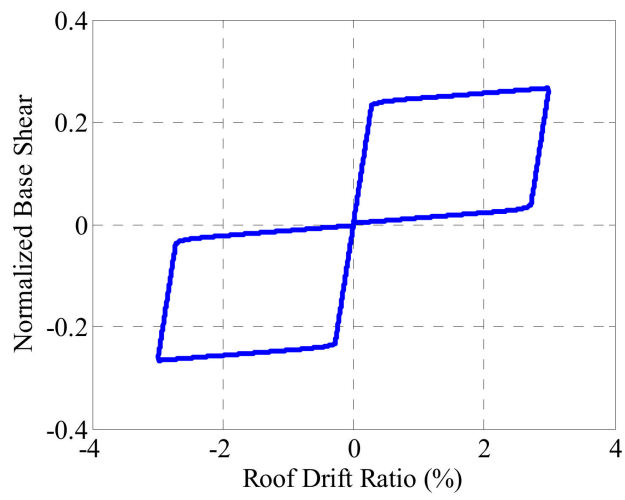

(b)

Figure 5. Cont. 


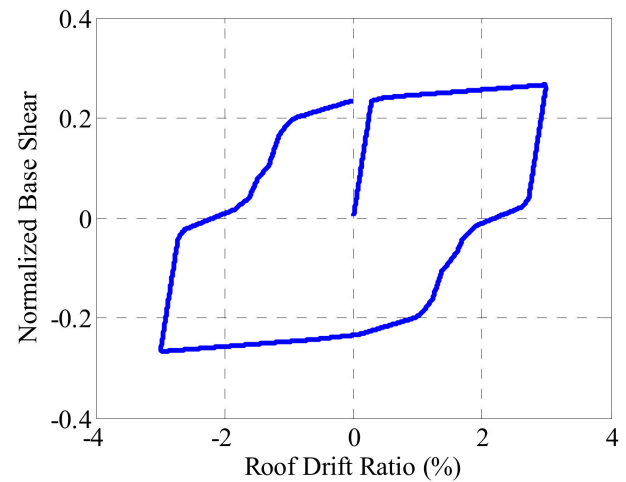

(c)

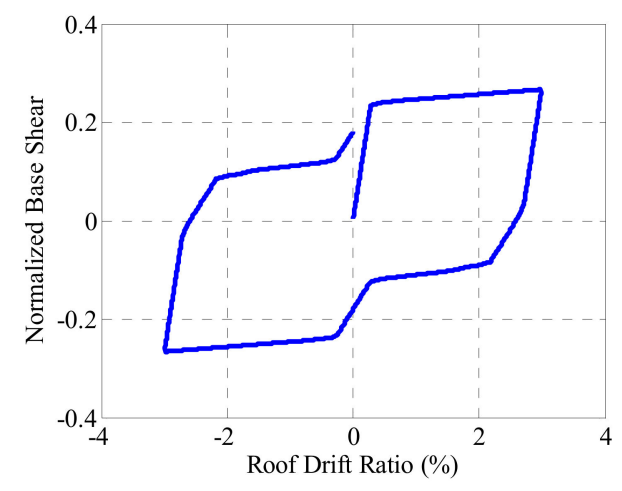

(e)

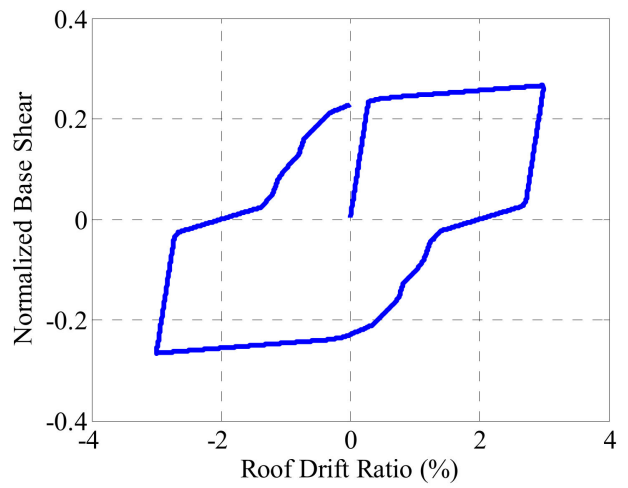

(d)

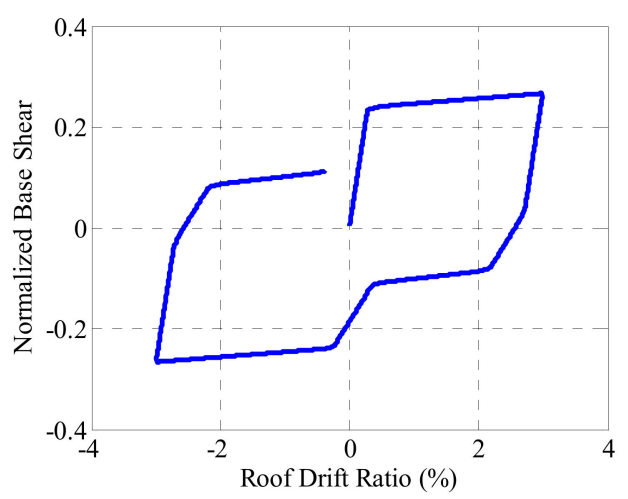

(f)

Figure 5. Cyclic pushover results of the steel frames: (a) S1; (b) S2; (c) S3; (d) S4; (e) S5; and (f) S6.

\section{Nonlinear Time History Analysis}

\subsection{Case Study}

To have a preliminary understanding of the seismic responses of the CBFs using hybrid bracing system, this subsection conducts nonlinear time history analysis on BRBF, SCCBF, and hybrid braced CBFs upon a single ground motion record by a case study. The ground motion record LA09 is artificially selected to demonstrate the effect of using hybrid bracing system. Figure 6 plots the time-history responses of roof drift ratios and roof accelerations for the frames under consideration. In the initial stage, the structures exhibit similar behavior until the ground motion excites the structures into serious nonlinearity. The peak roof drift ratios are approximately $0.66 \%$ and $1.05 \%$ for BRBF and SCCBF, respectively, which is primarily due to the fact that BRBF has much higher damping capacity than SCCBF. In terms of using hybrid braces, the corresponding deformation demands are between the BRBF and SCCBF, lying in the range from $0.91 \%$ to $1.01 \%$. However, as will be shown in the statistical results, the average peak story drift ratio shows a different observation, which will be discussed later on. 

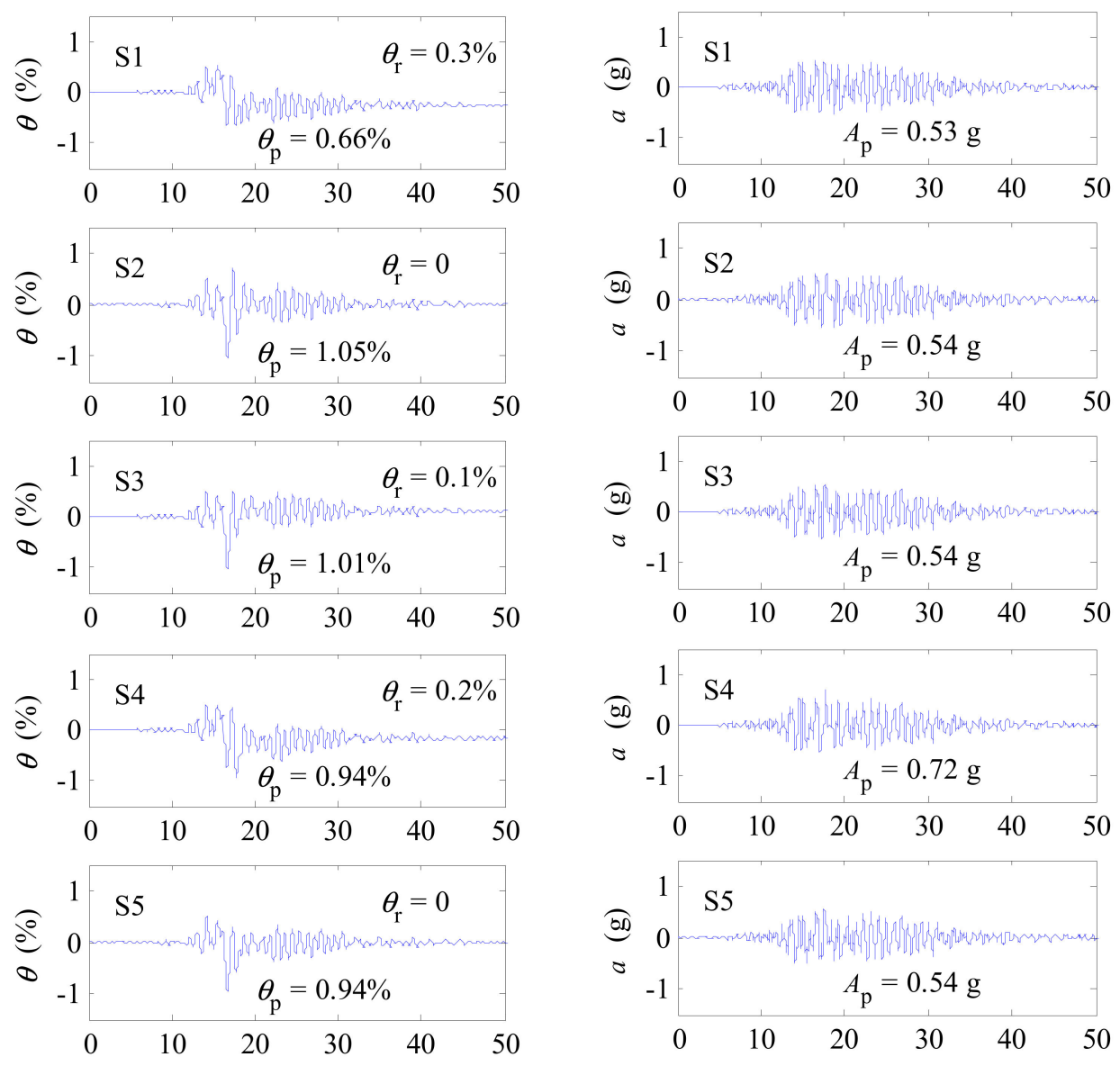

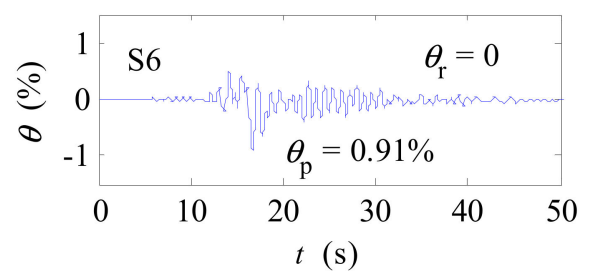

(a)

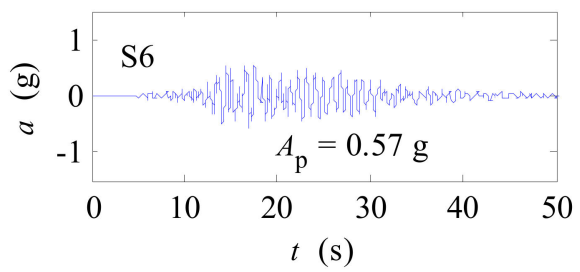

(b)

Figure 6. Response time history under ground motion LA09: (a) roof deformation; (b) roof acceleration.

The residual deformation demands are also a key index determining the seismic performance of seismic-resisting structures. This response parameter directly determines the repair cost and downtime duration after earthquakes. It is clear that the BRBF tends to produce biased deformation in a single side after being yielded, causing significant residual deformation at the end of the earthquake with $0.3 \%$ residual roof drift ratio. The SCCBF is found with entirely eliminated residual roof drift ratio at the end of vibration, thanks to the excellent recentering capability given by SCBs. Regarding the CBFs with hybrid bracing systems, the corresponding residual deformations are well reduced, compared with the BRBF. Therefore, the involvement of SCBs in a BRBF system may amplify the deformation demand to a certain degree but it remarkably decreases residual deformation demand.

Besides with the peak and residual deformation demands, the floor acceleration response is also examined. The results at the roof level are presented. It is interesting to note that, except for the frame S4, all the other frames suffer from nearly identical demands. This is because the yielding mechanism of the braces well caps the force demand in the entire structural system and consequently limits the increase of acceleration demand. The relatively large outcome generated in frame S4 is caused by 
higher mode effect. It means the significant nonlinearity of frame S4 involves the contribution from the 2nd or even higher modes. This phenomenon is similar to that noticed in a prior study [49].

Figure 7 plots the level-by-level responses throughout building height, including the peak story drift ratio, peak floor acceleration, and residual story drift ratio. This plot not only exhibits the magnitudes of considered demands but also displays the response deviation among different stories. Figure 7a shows that the SCCBF and BRBF exhibit similar peak deformation patterns over building height but that the former experiences higher demand by approximately $70 \%$. When some of BRBs are replaced by SCBs, the deformation demands will be increased. Taking frames S5 and S6 for example, both of which use BRBs and SCBs alternatively over all stories, they show similar deformation patterns. Although the peak story drift ratios are approximately $50 \%$ larger than the BRBF, they are well within the design targets of $1.5 \%$ as prescribed by the American Society of Civil Engineers (ASCE) code [50]. For peak floor accelerations, the smallest values are associated with the BRBF. The amplified accelerations are mostly found in the floors where the BRBs are replaced, which is due to the low damping capability of SCBs. Among the four hybrid bracing configurations, the types of S5 and S6 are more favorable than the others because of their smaller demands. In terms of the residual story drift ratio, as expected, significantly residual deformations are found in the BRBF. At the second story, it is approximately $0.5 \%$, implying the building is not suitable for repairing. However, the residual deformation demands are well reduced by installing SCBs, as evidenced by the results of SCCBF and hybrid bracing frames. It is also noted that structures S5 and S6 exhibit trivial demands over building height.

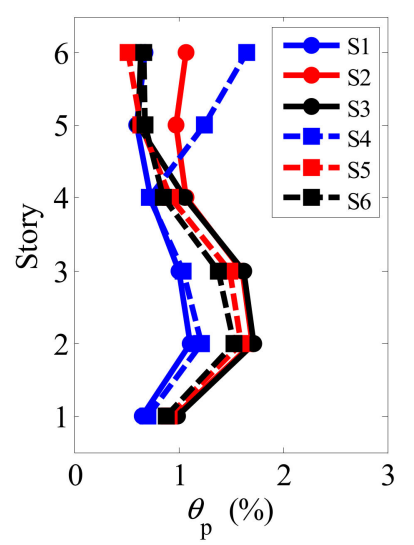

(a)

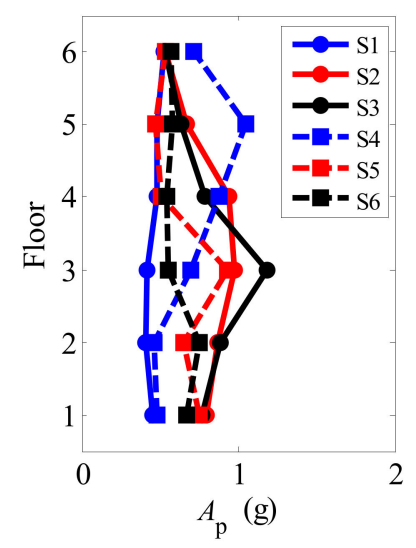

(b)

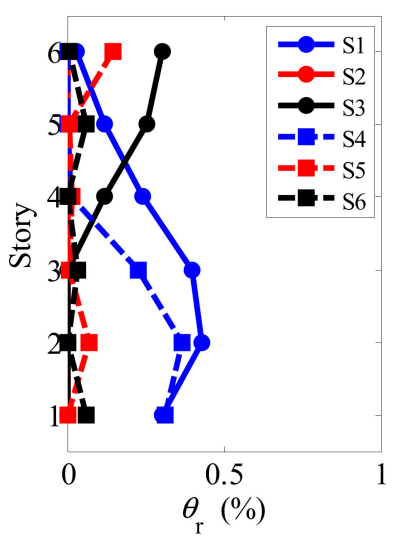

(c)

Figure 7. Seismic demands under ground motion LA09: (a) peak story drift ratio; (b) peak floor acceleration; (c) residual story drift ratio.

\subsection{Statistical Results}

As revealed by the spectral acceleration shown in Figure 4, remarkable record-to-record response deviation is noticed. Thus, the structural performance under an individual earthquake record does not necessarily stand for the central tendency when the structures are subject to a suite of ground motion records. Accordingly, the observation from the case study based on a single ground motion analysis is further examined through statistical analysis on all seismic analysis results. Figure 8 assembles the maximum story drift, maximum floor acceleration, and maximum residual story drift ratio under 20 ground motion records. 


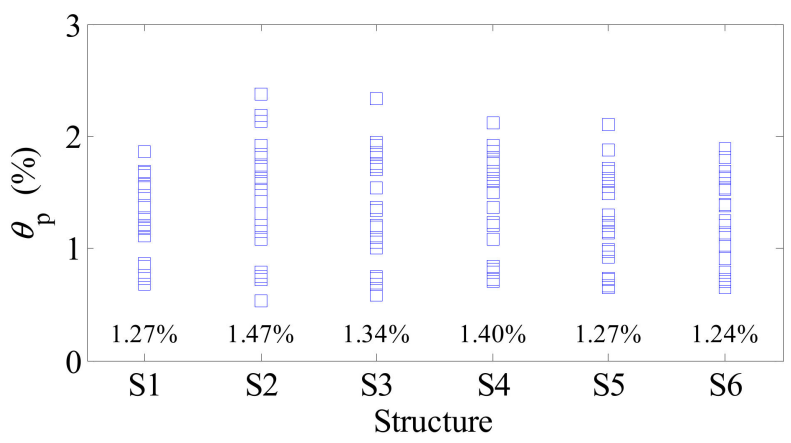

(a)

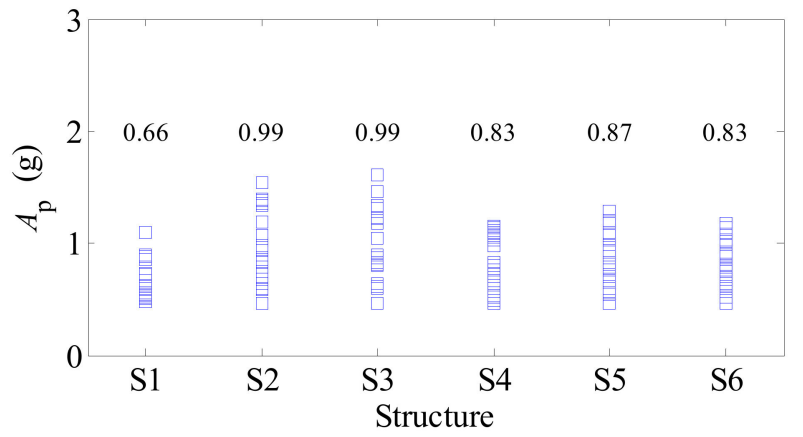

(b)

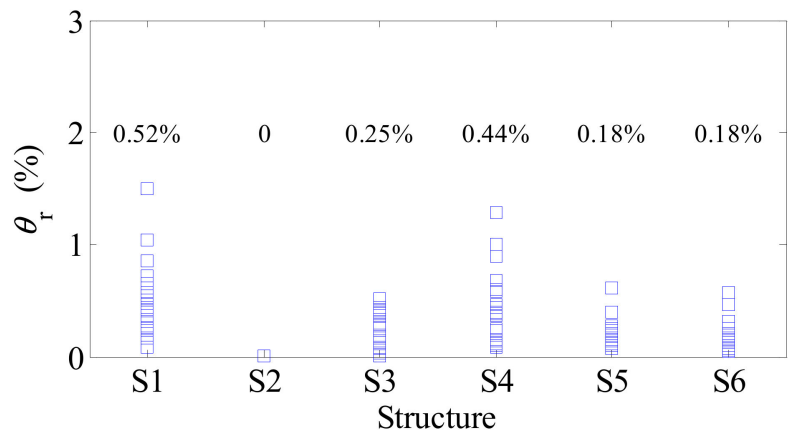

(c)

Figure 8. Seismic responses under the input ground motion records: (a) maximum transient story drift ratio; (b) maximum floor acceleration; and (c) maximum residual story drift ratio.

Figure 8a shows the scatter plot of the maximum story drift ratio for the structures under consideration. The mean values are calculated and put under the dots. Depending on the bracing configuration, the demands of hybrid braced CBFs can be larger or smaller than that of the pure BRBF. The mean values are $1.27 \%$ and $1.47 \%$ for the BRBF and the SCCBF, respectively. Although the equivalent damping ratio of $\mathrm{SCCBF}$ is half that of $\mathrm{BRBF}$, the deformation demand is only approximately $16 \%$ higher. Compared with the BRBF, the demands of S5 and S6 are equivalent or even smaller. Thus, when the BRBs are replaced by SCBs at some stories, the corresponding frames are possible to generate improved deformation performance to a certain degree. For frames of S3 and S4, they exhibit larger deformations than original BRBF. This indicates that the BRBs and SCBs are suggested to be installed alternatively along building height.

Figure $8 \mathrm{~b}$ presents the scattered results of maximum floor accelerations along with the mean values. The BRBF shows the smallest demands of $0.66 \mathrm{~g}$, due to the best energy dissipation capacity. The frames of S2 and S3 show the largest demands among all the frames with a mean value of $0.99 \mathrm{~g}$, attributed to the mild damping mechanism. For the frames of S4-S6, the acceleration demands are 
nearly identical, having middle values between that of BRBF and SCCBF. Thus, it can be anticipated that the engagement of SCBs would constantly increase floor acceleration demands.

Figure $8 \mathrm{c}$ assembles the residual story drift results. The comparison between S1 and S2 is sharp because using SCBs eliminates residual deformations for the structures. This is attributed to the excellent recentering capability of SCBs. Similar observations and explanations can be found in other studies [15,26,35-38]. The effect of combining SCBs on mitigating residual deformation is much more pronounced compared with the peak deformations and peak accelerations. As can be seen, the BRBF produces a mean residual story drift ratio over $0.5 \%$, which violates the repairing threshold [17]. This is completely eliminated by replacing all BRBs with SCBs. For the other cases, the residual deformation is reduced to different extents by combining SCBs in different stories. The most remarkable reduction is found in the frames of S5 and S6. The corresponding reduction ratio is approximately $65 \%$.

Figure 9 examined the story-by-story seismic performance by plotting the height-wise demands. For each story or floor level, the mean values are calculated and presented. The values in Figure 9 are slightly different from that in Figure 8 because the results in Figure 8 are the mean of the maximum transient responses over all levels, while that in Figure 9 are the mean of the maximum transient responses at the specific level. Consequently, the results in Figure 9 will be slightly smaller than that in Figure 8. Generally, a consistent observation can be made when recalling the scatter plots given by Figure 8 . The mean values of peak story drift ratios, residual story drift ratios, and peak floor accelerations over the building height are plotted to examine the distribution uniformity of the deformation demands. The smallest peak story drifts tend to occur at the first story due to the increased story stiffness contributed by the fixed column bases. The deformation demands of S5 and S6 are smaller than the BRBF at the upper two stories. The mean results of residual story drift ratios are well reduced in almost each story by introducing the SCBs. The combined frame tends to exhibit a more uniform deformation demand over the building height than the pure BRBF. Regarding the peak floor acceleration, frames S5 and S6 are comparable to the BRBF.

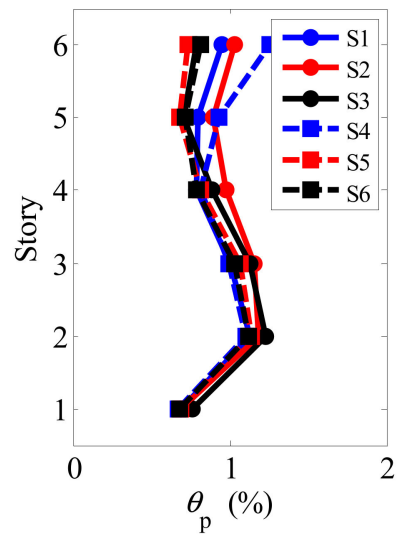

(a)

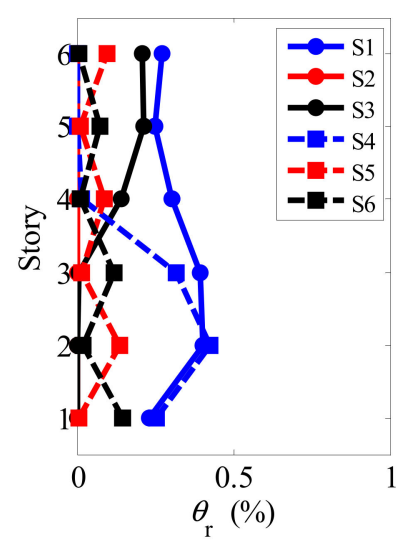

(b)

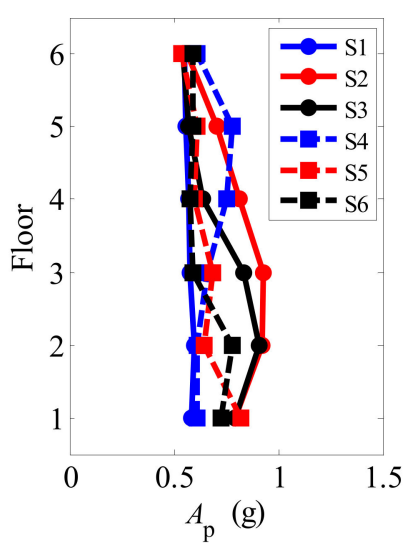

(c)

Figure 9. Seismic demands under the ground motion suite: (a) peak inter-story drift ratio; (b) residual inter-story drift ratio; and (c) peak floor accelerations.

Therefore, according to the assessment on the scattered maximum response and height-wise peak responses, it can be concluded that the frames of S5 and S6 use the most favorable hybrid bracing system among all the considered systems.

\section{Conclusions}

BRBFs tend to accumulate excessive residual deformation after earthquakes, which may prohibit the repairing work and cause long-term business downtime after earthquakes. On the other hand, SCBs are known for their excellent capability of recovering deformation. In order to address the problem for conventional BRBFs, this paper suggested using BRBs and SCBs together to form a hybrid 
bracing system. The proposed idea essentially combined the energy dissipation capacity of BRBs and the recentering capability of SCBs, which has never been reported in prior studies. The main assumption made in this analysis was that the fracture problem of braces could be avoided, which is also widely accepted in peer studies [6,13-15]. Thus, authors should understand current results with cautions. To validate the proposed methodology, intensive seismic analyses at the DBE seismic hazard level were conducted on six-story framing structures and the following conclusions can be obtained:

1. When the SCBs were installed to replace BRBs at certain stories, the global energy dissipation capacity will be deteriorated while the recentering capability was enhanced, according to the cyclic pushover results.

2. The hybrid bracing configurations that use SCBs and BRBs in alternative stories were suggested, considering such a placement reduced the maximum and residual story drift ratios by approximately $2 \%$ and $65 \%$, respectively, compared with the pure BRBF.

3. Although the residual deformation cannot be completely eliminated by using the hybrid bracing system, it was well reduced to approximately $0.1 \%$, which is small enough to carry out economical reparability.

4. The concept presented in the paper can shed light on the cases when different dissipative devices are used or when different structural typologies are considered.

Author Contributions: Conceptualization: R.C., D.H., and C.Q.; methodology: R.C. and C.Q.; software: R.C., C.Q., and D.H.; validation: R.C. and C.Q.; formal analysis: C.Q.; investigation: R.C. and C.Q.; resources: R.C., D.H., and C.Q.; data curation: D.H. and C.Q.; writing—original draft preparation: R.C. and D.H.; writing-review and editing: C.Q.; visualization: R.C., D.H., and C.Q.; supervision: R.C. and C.Q.; project administration: R.C. and D.H.; funding acquisition: R.C., D.H., and C.Q. All authors have read and agreed to the published version of the manuscript.

Funding: This research was funded by National Natural Science Foundation of China, grant number 51808317 and 51409045.

Conflicts of Interest: The authors declare no conflict of interest.

\section{References}

1. Downey, A.; Cao, L.; Laflamme, S.; Taylor, D.; Ricles, J. High capacity variable friction damper based on band brake technology. Eng. Struct. 2016, 113, 287-298. [CrossRef]

2. Downey, A.; Theisen, C.; Murphy, H.; Anastasi, N.; Laflamme, S. Cam-based passive variable friction device for structural control. Eng. Struct. 2019, 188, 430-439. [CrossRef]

3. Tajammolian, H.; Khoshnoudian, F.; Rezaei Rad, A.; Loghman, V. Seismic Fragility Assessment of Asymmetric Structures Supported on TCFP Bearings Subjected to Near-field Earthquakes. Structures 2018, 13, 66-78. [CrossRef]

4. Aghlara, R.; Tahir, M.M. A passive metallic damper with replaceable steel bar components for earthquake protection of structures. Eng. Struct. 2018, 159, 185-197. [CrossRef]

5. Rezaei Rad, A.; Banazadeh, M. Probabilistic risk-based performance evaluation of seismically base-isolated steel structures subjected to far-field earthquakes. Buildings 2018, 8, 128. [CrossRef]

6. Sabelli, R.; Mahin, S.; Chang, C. Seismic demands on steel braced frame buildings with buckling-restrained braces. Eng. Struct. 2003, 25, 655-666. [CrossRef]

7. Shen, J.; Seker, O.; Akbas, B.; Seker, P.; Momenzadeh, S.; Faytarouni, M. Seismic performance of concentrically braced frames with and without brace buckling. Eng. Struct. 2017, 141, 461-481. [CrossRef]

8. Hsiao, P.C.; Lehman, D.E.; Roeder, C.W. Improved analytical model for special concentrically braced frames. J. Constr. Steel Res. 2012, 73, 80-94. [CrossRef]

9. Simpson, B.G.; Mahin, S.A. Experimental and numerical investigation of strongback braced frame system to mitigate weak story behavior. J. Struct. Eng. 2017, 144, 04017211. [CrossRef]

10. Qu, B.; Liu, X.; Hou, H.; Qiu, C.; Hu, D. Testing of buckling-restrained braces with replaceable steel angle fuses. J. Struct. Eng. 2018, 144, 04018001. [CrossRef]

11. Ariyaratana, C.; Fahnestock, L.A. Evaluation of buckling-restrained braced frame seismic performance considering reserve strength. Eng. Struct. 2011, 33, 77-89. [CrossRef] 
12. Uang, C.M.; Nakashima, M.; Tsai, K.C. Research and application of buckling-restrained braced frames. Int. J. Steel Struct. 2004, 4, 301-313.

13. Tremblay, R.; Lacerte, M.; Christopoulos, C. Seismic response of multistory buildings with self-centering energy dissipative steel braces. J. Struct. Eng. 2008, 134, 108-120. [CrossRef]

14. Deylami, A.; Mahdavipour, M.A. Probabilistic seismic demand assessment of residual drift for Buckling-Restrained Braced Frames as a dual system. Struct. Saf. 2016, 58, 31-39. [CrossRef]

15. Qiu, C.; Zhang, Y.; Li, H.; Qu, B.; Hou, H.; Tian, L. Seismic performance of concentrically braced frames with non-buckling braces: A comparative study. Eng. Struct. 2018, 154, 93-102. [CrossRef]

16. Chancellor, N.; Eatherton, M.; Roke, D.; Akbaş, T. Self-centering seismic lateral force resisting systems: High performance structures for the city of tomorrow. Buildings 2014, 4, 520-548. [CrossRef]

17. McCormick, J.; Aburano, H.; Ikenaga, M.; Nakashima, M. Permissible residual deformation levels for building structures considering both safety and human elements. In Proceedings of the 14th World Conference on Earthquake Engineering, Beijing, China, 12-17 October 2008.

18. Eatherton, M.R.; Hajjar, J.F. Residual drifts of self-centering systems including effects of ambient building resistance. Earthq. Spectra 2011, 27, 719-744. [CrossRef]

19. Ricles, J.M.; Sause, R.; Garlock, M.M.; Zhao, C. Post-tensioned seismic resistant connections for steel frames. J. Struct. Eng. 2001, 127, 113-121. [CrossRef]

20. Tian, L.; Qiu, C. Controlling Residual Drift in BRBFs by Combining SCCBFs in Parallel. J. Perform. Constr. Fac. 2018, 32, 04018047. [CrossRef]

21. Liu, Y.; Wang, H.; Qiu, C.; Zhao, X. Seismic Behavior of Superelastic Shape Memory Alloy Spring in Base Isolation System of Multi-Story Steel Frame. Materials 2019, 12, 997. [CrossRef]

22. Zhu, S.; Zhang, Y. Seismic analysis of concentrically braced frame systems with self-centering friction damping braces. J. Struct. Eng. 2008, 134, 121-131. [CrossRef]

23. Clayton, P.; Berman, J.; Lowes, L. Seismic design and performance of self-centering steel plate shear walls. J. Struct. Eng. 2012, 138, 22-30. [CrossRef]

24. Seo, J.; Kim, Y.; Hu, J. Pilot study for investigating the cyclic behavior of slit damper systems with recentering shape memory alloy (SMA) bending bars used for seismic restrainers. Appl. Sci. 2015, 5, 187-208. [CrossRef]

25. Seo, J.; Hu, J. Seismic response and performance evaluation of self-centering LRB isolators installed on the CBF building under NF ground motions. Sustainability 2016, 8, 109. [CrossRef]

26. Qiu, C.; Zhu, S. Shake table test and numerical study of self-centering steel frame with SMA braces. Earthq. Eng. Struct. Dyn. 2017, 46, 117-137. [CrossRef]

27. Kiggins, S.; Uang, C.M. Reducing residual drift of buckling-restrained braced frames as a dual system. Eng. Struct. 2006, 28, 1525-1532. [CrossRef]

28. Qiu, C.; Tian, L. Feasibility analysis of SMA-based damping devices for use in seismic isolation of low-rise frame buildings. Int. J. Struct. Stab. Dyn. 2018, 18, 1850087. [CrossRef]

29. Dolce, M.; Cardone, D.; Marnetto, R. Implementation and testing of passive control devices based on shape memory alloys. Earthq. Eng. Struct. Dyn. 2000, 29, 945-968. [CrossRef]

30. Christopoulos, C.; Tremblay, R.; Kim, H.J.; Lacerte, M. Self-centering energy dissipative bracing system for the seismic resistance of structures: Development and validation. J. Struct. Eng. 2008, 134, 96-107. [CrossRef]

31. Xu, L.H.; Fan, X.W.; Li, Z.X. Development and experimental verification of a pre-pressed spring self-centering energy dissipation brace. Eng. Struct. 2016, 127, 49-61. [CrossRef]

32. Xu, L.H.; Xie, X.S.; Yao, S.Q.; Li, Z.X. Hysteretic behavior and failure mechanism of an assembled self-centering brace. B. Earthq. Eng. 2019, 17, 3573-3592. [CrossRef]

33. Ghowsi, A.F.; Faqiri, A.; Sahoo, D.R. Numerical Study on Cyclic Response of Self-centering Steel Buckling-Restrained Braces. In Recent Advances in Structural Engineering; Rao, A., Ramanjaneyulu, K., Eds.; Springer: Singapore, 2018; pp. 589-598. [CrossRef]

34. Hou, H.; Li, H.; Qiu, C.; Zhang, Y. Effect of hysteretic properties of SMAs on seismic behavior of self-centering concentrically braced frames. Struct. Control Hlth. 2018, 25, e2110. [CrossRef]

35. Qiu, C.; Zhao, X.; Zhang, Y.; Hou, H. Robustness of Performance-Based Plastic Design Method for SMABFs. Int. J. Steel Struct. 2019, 19, 787-805. [CrossRef]

36. Qiu, C.; Zhang, Y.; Qi, J.; Li, H. Seismic behavior of properly designed CBFs equipped with NiTi SMA braces. Smart Struct. Syst. 2018, 21, 479-491. 
37. Qiu, C.; Li, H.; Ji, K.; Hou, H.; Tian, L. Performance-based plastic design approach for multi-story self-centering concentrically braced frames using SMA braces. Eng. Struct. 2017, 153, 628-638. [CrossRef]

38. Qiu, C.X.; Zhu, S. Performance-based seismic design of self-centering steel frames with SMA-based braces. Eng. Struct. 2017, 130, 67-82. [CrossRef]

39. Christopoulos, C.; Filiatrault, A.; Folz, B. Seismic response of self-centring hysteretic SDOF systems. Earthq. Eng. Struct. Dyn. 2002, 31, 1131-1150. [CrossRef]

40. Zhang, Y.; Zhu, S. A shape memory alloy-based reusable hysteretic damper for seismic hazard mitigation. Smart Mater. Struct. 2007, 16, 1603. [CrossRef]

41. Erochko, J.; Christopoulos, C.; Tremblay, R.; Kim, H.J. Shake table testing and numerical simulation of a self-centering energy dissipative braced frame. Earthq. Eng. Struct. Dyn. 2013, 42, 1617-1635. [CrossRef]

42. Federal Emergency Management Agency. NEHRP Recommended Provisions for Seismic Regulations for New Buildings and Other Structures; Federal Emergency Management Agency: Washington, DC, USA, 1997.

43. Fahnestock, L.A.; Ricles, J.M.; Sause, R. Experimental evaluation of a large-scale buckling-restrained braced frame. J. Struct. Eng. 2007, 133, 1205-1214. [CrossRef]

44. OpenSees. Open system for Earthquake Engineering Simulation (OpenSees); v 2.4.1; Pacific Earthquake Engineering Research Center: Berkeley, CA, USA, 2013.

45. Neuenhofer, A.; Filippou, F.C. Evaluation of nonlinear frame finite-element models. J. Struct. Eng. 1997, 123, 958-966. [CrossRef]

46. Erochko, J.; Christopoulos, C.; Tremblay, R.; Choi, H. Residual drift response of SMRFs and BRB frames in steel buildings designed according to ASCE 7-05. J. Struct. Eng. 2010, 137, 589-599. [CrossRef]

47. Sommerville, P. Development of Ground Motion Time Histories for Phase 2 of the FEMA/SAC Steel Project; SAC Background Document SAC/BD-91/04; SAC Joint Venture: Sacramento, CA, USA, 1997.

48. MacRae, G.A.; Kawashima, K. Post-earthquake residual displacements of bilinear oscillators. Earthq. Eng. Struct. Dyn. 1997, 26, 701-716. [CrossRef]

49. Qiu, C.X.; Zhu, S. High-mode effects on seismic performance of multi-story self-centering braced steel frames. J. Constr. Steel Res. 2016, 119, 133-143. [CrossRef]

50. American Society of Civil Engineers. Minimum Design Loads for Buildings and Other Structures; American Society of Civil Engineers: Reston, VA, USA, 2010. 